\title{
Communication Technology and Application of Internet of Things (IoT) in Smart Home Environment
}

\author{
Sunguk Lee \\ Multimedia Engineering Department, Hannam University \\ 133 Ojeong-dong, Daeduk-gu, Daejeon, Korea \\ sulee0612@hnu.kr
}

\begin{abstract}
With significant development of smart and communication technology Internet of Things (IoT) is expected to play an important role of several application fields like healthcare, smart home, education and so on recently. The smart home technology which adopts IoT supports full connectivity of all devices not only internally but also externally. User can control and manage all devices connected with network remotely using mobile devices such as smart phone through mobile Internet. This paper represents overview of IoT technologies and applications for Smart Home. The communication technologies for IoT at home environment are also explained.
\end{abstract}

Keywords: Internet of Things, Smart Home, Home Area Network

\section{Introduction}

In order to provide improved home life of residence many technologies have been adopted at white appliances for many decades. In the early time the Smart Home $[1,2]$ was considered as just extended concept of building automation which can simply support control of light, air conditioner and home appliances like washer and refrigerators. Many home network protocols have been used for communication among home devices using power line, twisted line and Radio frequency as transmission medium.

In the beginning just small control packets have been used for home network. X10 protocol [3] using Power line communication (PLC) technology has supported maximum data rate of $120 \mathrm{bps}$ to turn off and on for light. Now day over 200Mbps of data rate can be supported by PLC [4] to scope with numerous appliances in home network and the large size data like as multimedia contents. Many wireless communication technologies such as Bluetooth, Zigbee and WIFI are also used for home network.

From late 1990's several standards for home networks have been proposed. Lonworks [5] and CEBus [6] were proposed for home automation. Lonworks uses power line and twisted line as transmission medium and supports 3-6 kbps of data rate with PLC. CEBus can use several kinds of medium such as radio frequency, power line, phone line. To support multimedia traffic like as audio/video data in home network UPnP(Universal Plug and Play)[7] was proposed. However, home network has not attracted by customer because of limitations of transmission medium and installation cost. These protocols are enough to provide connectivity among nodes in home network. However, connection with device which is located at outside of the home network has been limited because of using non-IP technology and access limitation to the Internet.

From 2000's the concept of ubiquitous network has been discussed widely. This concept is that every object like as home appliances has process and communication functions and connected to the network. However, the ubiquitous network has not 
deployed widely due to economic and technological problems such as scale of terminal, cost for sensors and network access. As technologies of sensor, actuators and communication are developed it is expected that limitation due to economic and technological problem will be removed soon. For the last decade new concept of communication which is called Internet of things $[8,9]$ has been gained significant attraction from academia and industrial field.

In this paper we focus on access technology and application \& service for smart home environment. The remainder of the paper is organized as follows. In the following section the overview of Internet of Things is explained. Section 3 describes IoT technologies for smart home environment. Applications and service of IoT in smart home is shown at section 4 . Section 5 concludes this paper.

\section{Overview of Internet of Things (IoT)}

The IoT abbreviation of Internet of Things was coined firstly at 1985. At that time the concept of IoT is to combine people, processes and devices with communication technology in order to exchange data for processing and management remotely. [8,10] Due to rapid development of communication, device, sensor and internet technologies it has been expected all objects including mobile devices surrounding us in the world are connected with each other using communication infrastructure. The sensor network and Radio Frequency identification (RFID) technologies have met this new communication and computing paradigm. The IoT has started to be discussed widely from 1999.

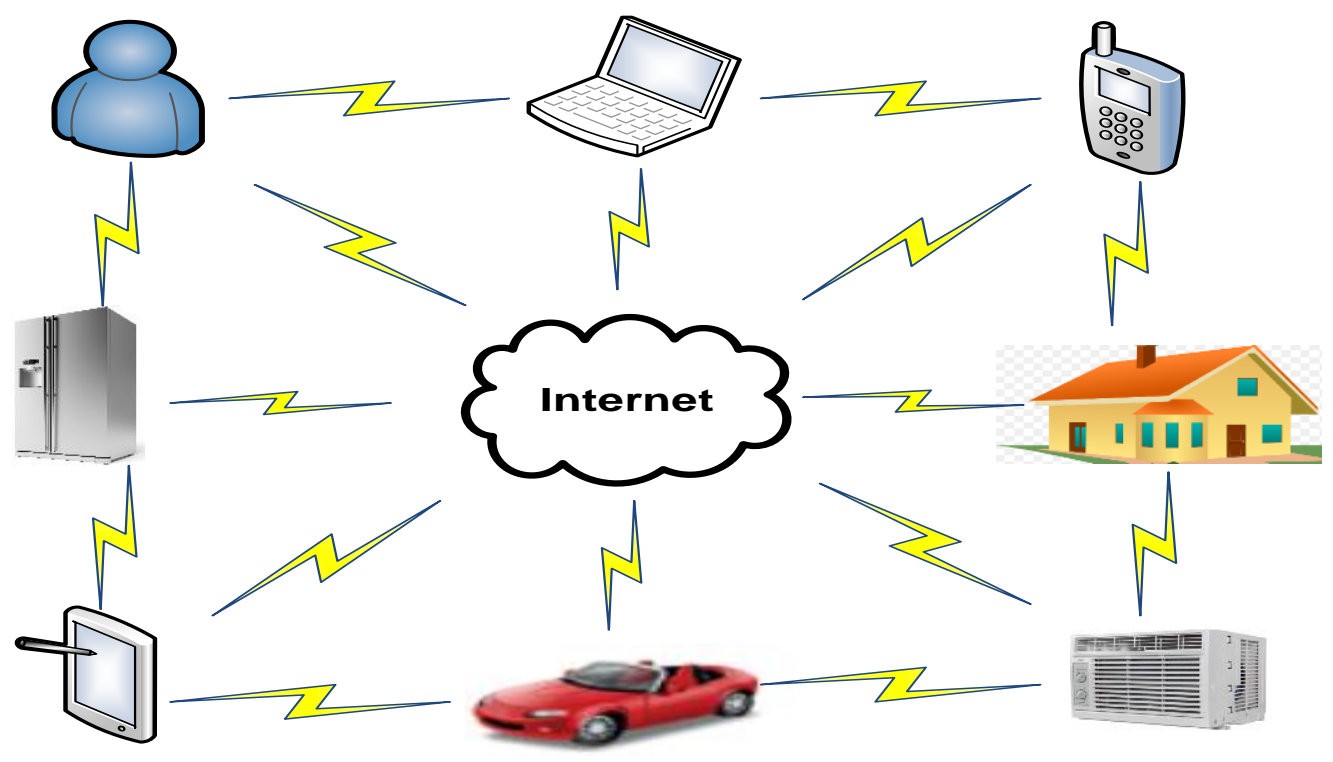

Figure 1. Configuration of IoT

The IoT can give connectivity of all objects such as mobile phone, PDA, smart devices, actuators and sensors to internet. Then these devices can interact in intelligent fashion with each other devices or people with unique addressing scheme to achieve some purposes in several fields as shown at figure.1 [9]. The concept of IoT is considered as promising technology for some application fields like as home, u-health care, disaster altering, environmental monitoring and so on. The IoT can be described as four major components as bellows [11] 
- Sensor

- Heterogeneous Access

- Information processing

- Application and services.

\section{Smart Home Technology with IoT}

The smart home technology in early stage was used to manage and control the limited home devices such as light and air conditioner. It just turns the light on and off and adjusts temperature of home with controlling air conditioner remotely through wire such as power line and dedicated twisted pair line. For this purpose, just small control packet was necessary to communicate between device and people with controller. The coverage of communication also limited at fixed spot in home. X-10 protocol with maximum data rate of $120 \mathrm{bps}$ was used to turn the light on and off using power line communication.

In recent years the smart technology has been rapidly developed. The smart devices are capable to obtain data from sensors, analyze the data and interpret it with processing function and give the instruction for accomplishment of some purpose or meaningful information to other devices or users. This smart technology has been embedded not only at computer and mobile phone but also at many devices surrounding us including home appliances such as TV, refrigerator and security system in home. Currently the smart technology can be embedded at almost electronic devices then every electronic device with smart technology can be member of an intergraded system with communication technology. Recently several kinds of technologies for internet, high speed access and mobile communication have been developed significantly too. Multimedia traffic can be supported at home environment with PLC, Ethernet and wireless LAN. The home network can be connected with outside with Internet. Now the mobile devices like as smart phone and tablet PC are also possible to connect with remote network through Internet. The development of these technologies make home network be capable to provide full connectivity and management of home devices not only internally but also externally. The smart home technology adopts the IoT and expands the coverage its of applications.

\subsection{Communication Technology of Smart Home with IoT}

The communication infrastructure for IoT smart home can be divided as two parts. The first one is for communication among devices in the house. The LAN (Local Area Network) supports small area connectivity such as home and building. Broad band PLC, Ethernet and IEEE802.11x are technologies for LAN. The PAN (Personal Area Network) [12] supports short distance connectivity for communication among personal devices like computer, telephone and personal digital devices. Bluetooth, Zigbee and RFID are technologies for PAN. The technologies of LAN and PAN are used for Home Area Network (HAN). The other one is network for communication between device in HAN and device in outside network. Wide Area Network (WAN) is used for this purpose. The cellular network technologies such as GSM, WiMAX and LTE are used for WAN. In this paper we focus on network for home area. Table 1 and 2 explain communication technologies for home IoT network with wired and wireless transmission medium respectively. 


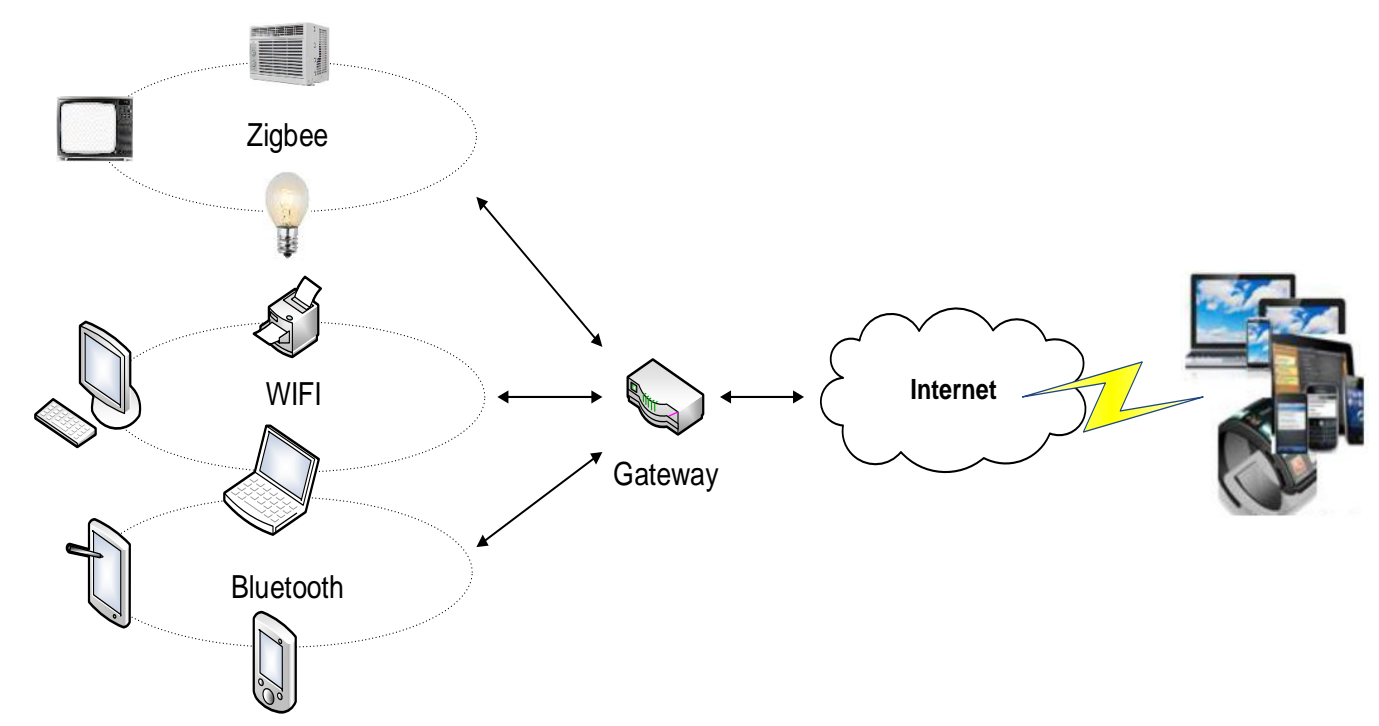

Figure 2. Example of Smart Home System

These communication technologies are used technologies at several fields. The communication technologies for local area can support about $100 \mathrm{M}$ of transmission range. However, PAN normally supports very short range, about 10M. In home many kind of electronic devices may be used in same space with different communication technology. Computer and laptop may use wireless LAN (IEEE 802.11x) technology for communication. To share music or file in short distance Bluetooth is used widely. Therefore, Home IoT network may consist of several sub networks using different communication technologies. Figure 2 shows example of smart home system with several sub networks like Bluetooth, Zigbee and WIFI. Some examples of sub network for home IoT network are described as bellows.

- Wireless Local Area Network and Ethernet for computer, laptop and tablet PC

- Bluetooth for file and music sharing, portable speaker, wireless keyboard and so on

- UWB for multimedia traffic in short distance

- Zigbee (IEEE 802.15) for sensors for air conditioner and security system

- $\quad$ PLC for measuring power consumption 
Table 1. Technologies for Home loT Network using Wire Technology

\begin{tabular}{|c|c|c|c|c|}
\hline Technology & $\begin{array}{c}\text { Coverage } \\
\text { Area }\end{array}$ & $\begin{array}{c}\text { Data rate } \\
\text { (Mbps) }\end{array}$ & Typical Application & $\begin{array}{c}\text { Transmission } \\
\text { medium }\end{array}$ \\
\hline Ethernet & Local Area & 100 & Data network & $\begin{array}{c}\text { Twisted pair or } \\
\text { fiber }\end{array}$ \\
\hline MoCA & Local Area & $\begin{array}{c}100 \\
\text { (MoCA 1.0) }\end{array}$ & $\begin{array}{c}\text { Multimedia and } \\
\text { data Network }\end{array}$ & Coaxial cable \\
\hline PLC & Local Area & $\begin{array}{c}200 \\
\text { (BB-PLC) }\end{array}$ & $\begin{array}{c}\text { Control and data } \\
\text { network }\end{array}$ & Power line. \\
\hline Home PNA & Local Area & $\begin{array}{c}32 \\
\text { (Home PNA } \\
2.0)\end{array}$ & Data network & Phone line \\
\hline
\end{tabular}

Table 2. Technologies for Home loT Network using Wireless Technology

\begin{tabular}{|c|c|c|c|c|}
\hline Technology & $\begin{array}{c}\text { Coverage } \\
\text { Area }\end{array}$ & Data rate & Typical Application & $\begin{array}{c}\text { Transmission } \\
\text { medium }\end{array}$ \\
\hline Z-wave & Local Area & 0.1 & Home automation & $\begin{array}{c}\text { Radio } \\
\text { transmission }\end{array}$ \\
\hline WiFi & Local Area & 100 & Data Network & $\begin{array}{c}\text { Radio } \\
\text { transmission }\end{array}$ \\
\hline SRD & $\begin{array}{c}\text { Personal } \\
\text { Area }\end{array}$ & Up to 0.02 & RFID & $\begin{array}{c}\text { Radio } \\
\text { transmission }\end{array}$ \\
\hline Zluetooth & $\begin{array}{c}\text { Personal } \\
\text { Area }\end{array}$ & 3 & $\begin{array}{c}\text { Music sharing and } \\
\text { playing }\end{array}$ & $\begin{array}{c}\text { Radio } \\
\text { transmission }\end{array}$ \\
\hline UWB & $\begin{array}{c}\text { Personal } \\
\text { Area }\end{array}$ & Up to 0.25 & $\begin{array}{c}\text { Sensing and } \\
\text { Monitoring }\end{array}$ & $\begin{array}{c}\text { Radio } \\
\text { transmission }\end{array}$ \\
\hline Arrea & Over 100 & $\begin{array}{c}\text { Multimedia, file } \\
\text { sharing }\end{array}$ & $\begin{array}{c}\text { Radio } \\
\text { transmission }\end{array}$ \\
\hline
\end{tabular}

\subsection{Configuration of Smart Home IoT Network}

To support connectivity among devices in home network two kinds of network configurations can be used normally. Theses network configurations are as below:

- Peer to Peer Network Configuration

- Server - Client Network Configuration

UPnP (Universal Plug and Play) [7] with IP based technology uses peer to peer communication to support indoor connectivity for controlling smart home appliances. The peer to peer network provides direct connection between device and device. In the server -client network has a server in the middle of devices which communicate with each other. The IoT service server may have function of management of home IoT members. The server - Client network is used at OneM2M [13]. The gateway may also be used for internet connection to control and manage the smart device remotely. The hybrid network which uses both peer to peer and client-server network is also used to support connectivity for smart home. These network configurations are shown at figure 3 . 

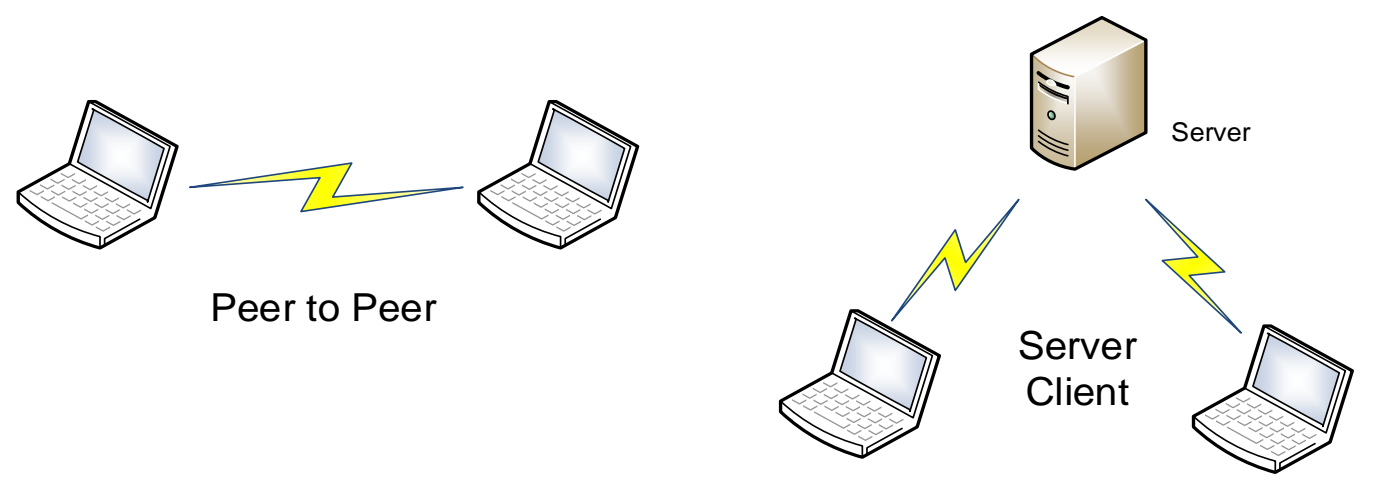

Figure 3. Network Configurations at Home

\section{Applications and Service of IoT at Smart Home}

As development of smart device and communication technologies the IoT technologies are adopted at several fields. The smart white appliances come into the market and many IoT base services for smart home have been introduced by several companies. Also the mobile devices play an important role of IoT at smart home. The application at mobile phone can control and manage the IoT devices in home remotly. The smart white appliances or smart home automation system can send information of current status such as temperature to user who is out of home with mobile Internet. The user also can send instruction to home automation system through smart mobile device. The examples of IoT applications in smart home are as follows:

- Control the smart home appliances

- Home Energy management system as part of smart grid

- $\quad$ Cooperation with U health care system

- $\quad$ Smart Home Security system

- $\quad$ Home Entertainment system

Apple released "Homekit"[14] which is a framework for communication and control of devices in home as developer tool. Smart phone with iOS can control every home device which works with Apple Homekit. The Homekit can support control of smart door lock, light system, camera, air conditioner \& heater and so on. Home energy management system collect power consumption information of home appliances and control the energy consumption to decrease utility fee. LG showed Smart InstaView Refrigerator at CES 2017. The user can check and manage the food in the refrigerator remotely. This smart refrigerator also can provide recipe and entertainment function with Amozon's Alexa for AI voice assistance. 


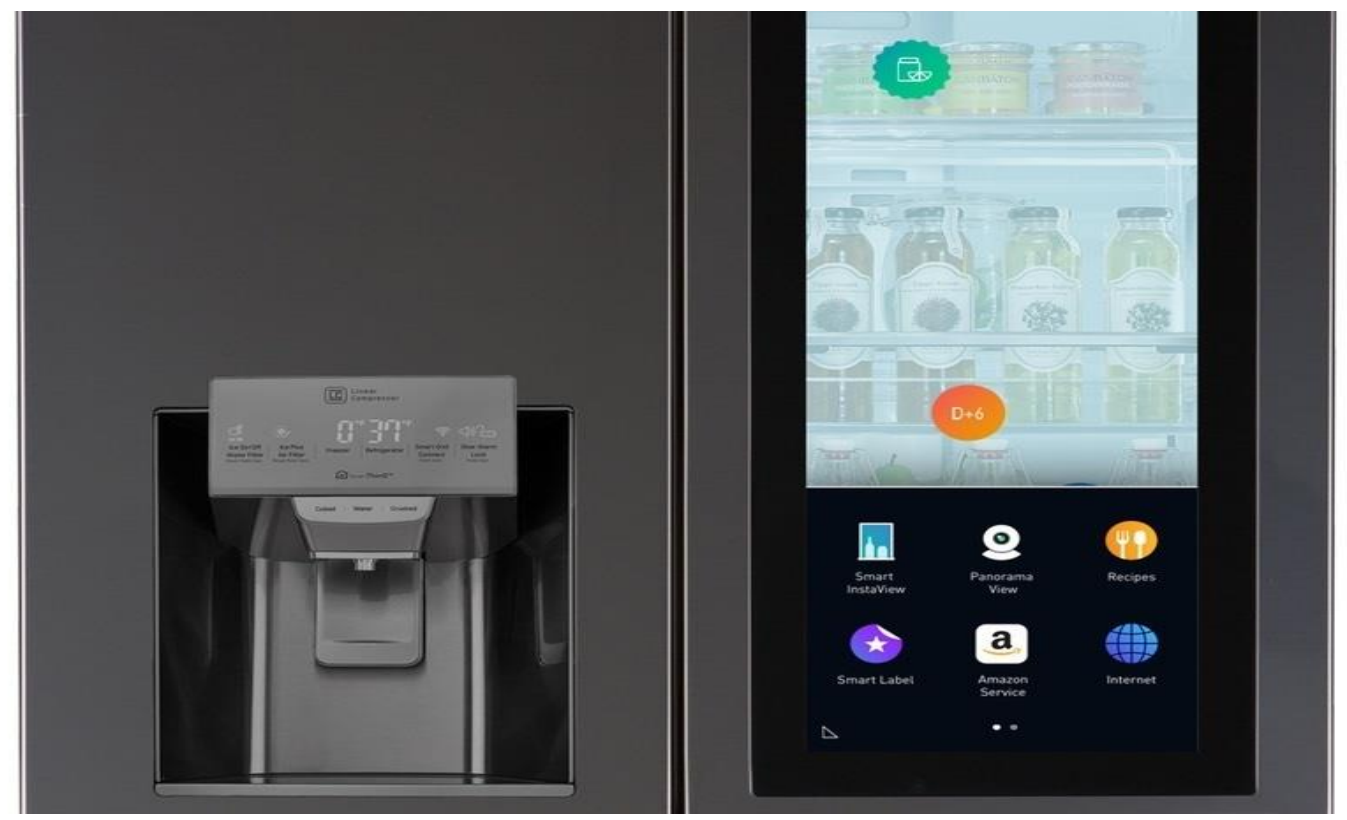

Figure 4. LG Smart Refrigerator InstaView [15]

\section{Conclusion}

Originally smart home which is called also home automation was used just for control and management of simple device such as light, air-conditioned in home environment. Due to recent development of Internet and smart technologies IoT has been gained significant attraction as an promising technology for novel services in innumerous application domains like as smart home, healthcare, industry, transportation and so on. In this paper, we introduce the concept of IoT and its application at smart home environment. Also the communication technologies for indoor connection are explained and applications of IoT for smart home including home IoT products are introduced.

\section{References}

[1] V. Ricquebourg, D. Menga, D Durand Bruno Marhic, L. Delahoche and C. Loge, "The Smart Home Concept: our immediate future", IEEE International Conference on E-Learning in Industrial Electronics, (2006), pp. 23-28.

[2] https://en.wikipedia.org/wiki/Home_automation.

[3] http://www.x10.com/support/technology.

[4] Homeplug Alliance, http://www.homeplug.org.

[5] https://en.wikipedia.org/wiki/LonWorks.

[6] https://en.wikipedia.org/wiki/CEBus

[7] UPnPForum, Enabling Standard IoT: Futureproofingdevice communications, 2014.

[8] https://en.wikipedia.org/wiki/Internet_of_things.

[9] L. Atzori, A. Iera and G. Morabito, “The Internet of Things: A survey", Elsevier, Computer Networks, (2010), pp. 2787-2805.

[10] S. Madakam, R. Ramswamy and S. Tripathi, "Internet of Things(IoT) : A Literature review" Journal of Computer and Communications, (2015), pp.164-173

[11] M. Chen, J. Wan and F. Li, "Machine-to-Machine Communications: Architectures, Standards and Applications", KSII Transaction on Internet and Information System, vol. 6, no. 2, (2012) February, pp. 480-497.

[12] https://en.wikipedia.org/wiki/Personal_area_network

[13] OneM2M, http://www.onem2.org

[14] https://developer.apple.com/homekit/

[15] http://core0.staticworld.net/images/article/2017/01/lg-smart-instaview-100701969-orig.jpg. 
International Journal of Control and Automation Vol.10, No.3 (2017) 